\title{
The Factors on Elderly Employment Project Outcome: Appropriation of work, Job Training Satisfaction, Intra-organizational Cooperation
}

\author{
Cin Jae Chang
}

\begin{abstract}
The purpose of the study was to examine the structural relationship among project outcome, appropriation of work, job training satisfaction, intra-organizational cooperation realized by the working-level officials. An analysis was conducted on 657 participants from the data of the '2011 Elderly Employment Project Executing Organization Survey'. The major findings were as follows: First, appropriation of work and intra-organizational cooperation had positive effects to project outcome. Second, appropriation of work and job training satisfaction had positive effects to intra-organizational cooperation. Third, appropriation of work had mediator effects to project outcome through intra-organizational cooperation. Based on the results, the implications for social work practice and policy were suggested.
\end{abstract}

Index Terms-Appropriation of work, intra-organizational cooperation, job training satisfaction, elderly employment project outcome.

\section{INTRODUCTION}

Recently, Republic of Korea's elderly population is showing enormous increasing trend. UN (United Nations) classifies society's aging degree by elderly ratio. UN classifies the society as Aging Society if more than $7 \%$ of the population is over 65 , Aged Society if more than $14 \%$ is, and Super-Aged Society if more than $20 \%$ is. ROK has entered Aging Society in 2000, and is expected to enter Aged Society in 2018 and Super-Aged Society in 2026. Based on this calculation, ROK will take about 18 years to enter Aged Society. This calculation shows how severe this problem is for Korea as it is 115 years for France, 72 years for the U.S., and 24 years for Japan which is also experiencing rapid society aging problem [1]. Therefore, Korea's aging society is a social problem due to its size and speed, requiring national intervention.

Increase in elderly population should be considered national threat as it not only decrease productivity and increase social burden, but also cause conflict between generations. Hereupon, Korea is carrying out 'Elderly Employment Project' to prepare various problems caused from the aging society. Elderly Employment Project is a project which supplies specialized jobs to elderly people among whole country who wish to work, resulting in offering chance to increase income and community participation for the elderly [2], showing recent trend of quantitative

Manuscript received August 4, 2014; revised October 13, 2014.

Cin Jae Chang is with the Seoul Jangsin University, 145 Gyungan-ro, Gwangju-si, Gyunggi-do, 464-742, South Korea (e-mail:jangsin@sjs.ac.kr). expansion. The jobs offered to the elderly increased to 261,598 in 2013, nearly over 7 times to that of from 35,127 in 2004 [3]. In 2014, about 287 billion won, which is 58.6 billion won more than last years, was invested, resulting in expansion of financial scale along with number of participants [2].

As the quantitative expansion for Elderly Employment Project is visualized, the studies to evaluate the effectiveness of the project have started, mostly focusing on project's financial, medical, and psycho-social effect. For the economic effect derived from the Elderly Employment Project, there has been increase in participant's income and decrease in poverty ratio [4], and for the medical effect, there has been decrease in medical treatment cost due to increase in health level [5]. For the psycho-social effect, participating in the Elderly Employment Project shows positive effect on participant's satisfaction of life and mental health [6].

However, in order to closely examine the policy-effectiveness of Elderly Employment Project, not only participants who are consumer, but also in supplier's point of view should project's outcome analysis. In other words, outcome analysis should be attempted in multilateral point of view. Among these, social welfare human resources, which are suppliers in social welfare policy perspective, function to directly affect the necessary activities for organization's survival [7], [8], resulting in their awareness of project outcome being very important factor to influence future project continuity.

On the other hand, Elderly Employment Project unites with Ministry of Health \& Welfare, Korea Labor Force Development Institute for the aged, regional local government, local governments, and implementation institutions to execute various roles respectively. However, their role is not mutually exclusive, but rather is overlapping. Moreover, since each organization's ways of operation are to execute by some independent organization or to authorize project execution to private organization, they generally differ from each other. In this process, discovering and managing job fitting regional condition and characteristic of elderly mostly depends on working level officials. Therefore, the project outcome may differ as officials are generally affiliated to different type of organization and therefore has difference in awareness of their service [9].

Generally, the non-profit organization's project outcome is determined by how much the project's purpose and goal has been accomplished [10], [11]. Especially for private organization participating in Elderly Employment Project, unlike local governments, which is obligated to manage the 
project and support operations, can voluntarily decide whether to participate in the project depending on how much the project is contributing to organization's effectivity. Therefore, whether or not to continue or expand the project indicates the purpose private organization has in executing the project and is a direct index to interpret outcome.

In preceding studies, the various factors having statistically significant effects on project outcome, especially ones related to organization's work characteristics, have been reported [12]. The factors among organization's work characteristics related to the work itself are work content factors such as appropriation of work, job training, and related organization's cooperation, work environment factors, and organization's external environment factors [13], [14]. The appropriation of work is a variable which is included in work content factor, composed and divided of work range and role vagueness, and shows statistically significant increase of work satisfaction and project outcome [15]. The job training is generally classified as work environment factor and intra-organizational cooperation is as organization's external environment. More these two factors are perceived as positive by the working level officials, higher the work satisfaction and project outcome becomes [16]. Also, the organization network such as intra-organizational cooperation is one of various factors which increase the organization effectivity [8] along with effectivity of organization's internal environmental factors, resulting in becoming factor mediating the work content factor, work environment factor, and project outcome.

From this point of view, in this study, the main factors related to project outcome realized by the working-level officials are work content factor (appropriation of work) and work environment factor (job training satisfaction). From this the factor has selected other organization environment factor (intra-organizational cooperation). In detail, this study discloses the structure and path the Elderly Employment Project working level officials' appropriation of work, job training satisfaction, and intra-organizational cooperation have what kind of relationship between project outcome and affects it.

\section{RESEARCH METHOD}

\section{A. Research Model}

In this study, I have selected appropriation of work, job training satisfaction, and intra-organizational cooperation as variable related to project outcome based on the discussion of Elderly Employment Project outcome related factors. The structural equation model between the variables is as shown in Fig. 1.

\section{B. Method of Analysis}

The data was analyzed as follows.

First, data of socio-demographics, and the characteristics of project outcome, appropriation of work, job training satisfaction and intra-organizational cooperation were analyzed through frequency and descriptive analysis with SPSS 22.0 for windows.

Second, the Structural Equation Modeling with AMOS
21.0 used to analyze, which estimated the relationship among major variables, mediate effect of mediator variables, and independent variables.

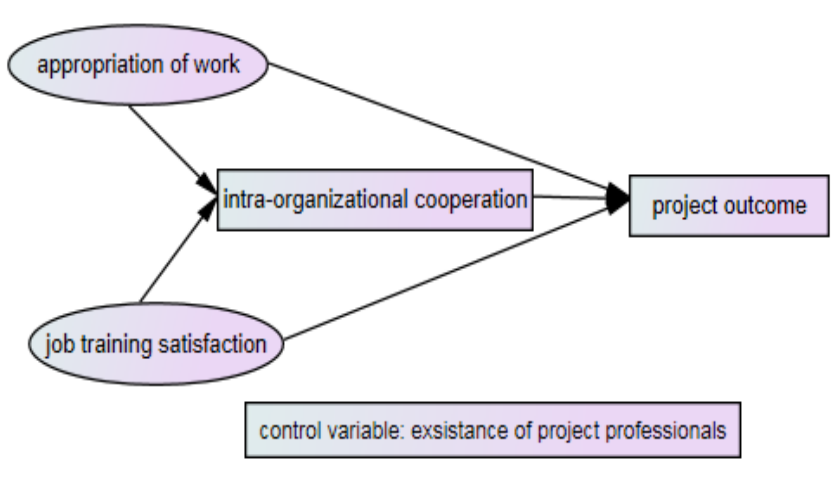

Fig. 1. Research model.

\section{Samples}

The object of the study is data from '2011 Elderly Employment Project Executing Organization Survey'. There are 120 local government organizations and 657 nonprofit organizations participating in the Elderly Employment Project. The collected data is from 2011 National (excluding Jeju and Sejong city) Elderly Employment Project participating organizations, 777 organizations in total, and in this study, 657 of the nonprofit organization's data has been extracted and applied in analysis.

\section{Measure}

\section{1) Dependent variable}

\section{a) Project outcome}

The project outcome was measured by the project manager's perception of the project's expansion expectation. 'I want the project to diminish or shut down', 'I want status quo', 'I want to expand the business' is the 3 point criteria measurement. Higher the point, more positive the project outcome is perceived.

\section{2) Independent variables}

\section{b) Appropriation of work}

The appropriation of work is composed of 3 criteria such as work form, responsible work amount, and responsible work content. The answer was measured by 'very suitable, suitable, normal, a not suitable'. The researcher has reverse questioned and higher the point means higher the appropriation of work. The reliability value of this scale was Cronbach's alpha of .902, showing high internal consistency reliability.

\section{c) Job training satisfaction}

The job training satisfaction is composed of 4 criteria such as 'overall satisfaction about the education, the appropriateness of education difficulty, the appropriateness of education number and time, appropriateness of teaching personnel'. The answer was measured by 5 point limit criteria of 'not at all appropriate, somewhat not appropriate, normal, appropriate, a very appropriate'. Higher the point is, the higher job training satisfaction is. The reliability value of this scale was Cronbach's alpha of .908 . 


\section{d) Intra-organizational cooperation}

The intra-organizational cooperation was measured by 'the cooperation relationship between related organizations of the project' with answers of 'very good, somewhat good, normal, not good, a very bad.' The answers were recoded by the researcher, meaning higher the point, higher the cooperation between related organizations.

\section{RESULTS}

\section{A. Socio-Demographics of Respondents}

TABLE I: SOCIO-DEMOGRAPHICS OF RESPONDENTS

\begin{tabular}{|c|c|c|c|}
\hline Classification & & Frequency & Ratio (\%) \\
\hline \multirow{7}{*}{$\begin{array}{l}\text { Institutional } \\
\text { Type }\end{array}$} & Senior Club & 61 & 9.3 \\
\hline & $\begin{array}{l}\text { Seniors Welfare } \\
\text { Community Center }\end{array}$ & 148 & 22.5 \\
\hline & $\begin{array}{l}\text { Comprehensive Social } \\
\text { Welfare Center }\end{array}$ & 130 & 19.8 \\
\hline & $\begin{array}{l}\text { Rehabilitation Center for } \\
\text { the Disabled }\end{array}$ & 1 & 0.2 \\
\hline & Senior Welfare Center & 110 & 16.7 \\
\hline & $\begin{array}{l}\text { Korea Senior Citizen's } \\
\text { Association }\end{array}$ & 172 & 26.2 \\
\hline & Other Institutions & 35 & 5.3 \\
\hline \multirow{7}{*}{$\begin{array}{l}\text { Main Work of } \\
\text { the Institution }\end{array}$} & Project Promotion & 50 & 7.6 \\
\hline & Job Training & 73 & 11.1 \\
\hline & $\begin{array}{l}\text { Project Settlement } \\
\text { Guidance in Early Stage }\end{array}$ & 87 & 13.2 \\
\hline & Monitoring & 194 & 29.5 \\
\hline & $\begin{array}{l}\text { Additional Support for } \\
\text { the Weak Program }\end{array}$ & 41 & 6.2 \\
\hline & Evaluation & 144 & 21.9 \\
\hline & $\begin{array}{l}\text { Vitalization of } \\
\text { Cooperation System }\end{array}$ & 68 & 10.4 \\
\hline $\begin{array}{l}\text { Existence of } \\
\text { Project } \\
\text { Complete } \\
\text { Charge } \\
\text { Department }\end{array}$ & Not Exist & 423 & 35.6 \\
\hline $\begin{array}{l}\text { Existence of } \\
\text { Project } \\
\text { Professionals }\end{array}$ & Not Exist & 185 & 71.8 \\
\hline
\end{tabular}

\section{B. Descriptive Statistics of Variables}

The descriptive statistics for the base analysis of the study's main variables are shown in Table II. To meet the stationary to apply the structural equation, I examined if each variables are following the normal distribution. [17] proposed the standard of normal distribution and all of the applied variables have met the standard, resulting in meeting the normal distribution requirements.

TABLE II: DESCRIPTIVE STATISTICS OF VARIABLES

\begin{tabular}{lcccc} 
Variables & Mean & S.E. & Skewness & Kurtosis \\
& & & & \\
\hline Project Outcome & 2.391 & .590 & -.375 & -.696 \\
Appropriation of Work & 3.887 & .632 & -.518 & 1.644 \\
Job Training Satisfaction & 3.437 & .638 & -.360 & 1.390 \\
Intra-organizational & 3.808 & .759 & -.420 & .593 \\
Cooperation & & & & \\
\hline \hline
\end{tabular}

\section{Correlation Among Variables}

TABLE III: CORRELATION AMONG VARIABLES

\begin{tabular}{llllll}
\hline \hline & (1) & (2) & (3) & (4) & (5) \\
\hline (1) & 1 & & & & \\
(2) & $.106 * *$ & 1 & & & \\
(3) & $.100 *$ & $.177 * *$ & 1 & & \\
(4) & $.099 *$ & $.157 * *$ & $.127 * *$ & 1 & \\
(5) & -.060 & .052 & -.011 & -.050 & 1 \\
\hline \hline
\end{tabular}

$\left.*_{p}<.05, * * p<.01,1\right)$ Job training satisfaction, 2) Appropriation of work, 3) Intra-organizational cooperation,4) Project outcome,5) Existence of project professionals.

All measured variables within the structural model were examined correlation analysis. As showed in Table III, the research variables totally showed significant relationship with one another at the level of $p<.01$ or $p<05$ except the control one. The values of VIF were rage from 1.007 to 1.044 , thus multi-collinearity among variables was not found.

\section{Structural Model}

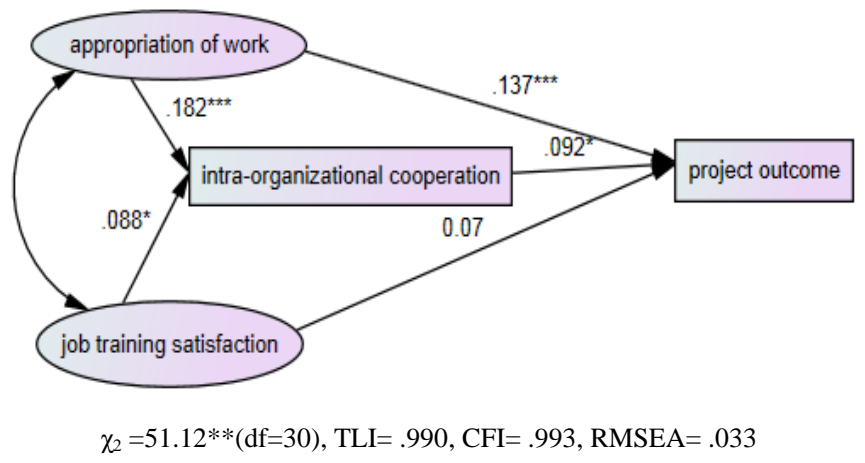

Fig. 2. Structural model.

The analysis of appropriation of work and job training satisfaction as antecedent, intra-organizational cooperation as mediating variable, and project outcome as consequence is as follows. To check the goodness of fit of the research model, I've checked the $\chi_{2}$, TLI, CFI, RMSEA indices. The goodness of fit indices were $\chi_{2}=51.12 * *(\mathrm{df}=30)$, TLI=.990, CFI=.993, RMSEA $=.033$. These results indicate this model is appropriate model.

This structural model's path coefficients are proposed in Fig. 2 and Table III. To examine the path coefficient among each variables in detail, the path coefficient from appropriation of work to project outcome is137, path coefficient from intra-organizational cooperation to project outcome is 092, showing more appropriate the manager perceive the responsible work, and more the cooperation between related organization is done, higher the outcome is. However, there is no statistically significant path from the job training to the project outcome. The path coefficient from the appropriation of work to intra-organizational cooperation is 182 and path coefficient from job training satisfaction to the intra-organizational cooperation is .088 , showing higher the appropriation of work is and higher the job training satisfaction is, the more cooperation between projects related organization can be achieved. 
TABLE IV: STRUCTURAL MODEL'S PATH COEFFICIENT

\begin{tabular}{|c|c|c|c|c|}
\hline Measured variable & B & $\beta$ & S.E. & $\begin{array}{l}\text { Critical } \\
\text { Ratio }\end{array}$ \\
\hline $\begin{array}{l}\text { Appropriation of Work } \\
\rightarrow \text { Project Outcome }\end{array}$ & .149 & .137 & .045 & $3.315^{* * *}$ \\
\hline $\begin{array}{l}\text { Job Training Satisfaction } \\
\rightarrow \text { Project Outcome }\end{array}$ & .066 & .070 & .038 & 1.734 \\
\hline $\begin{array}{l}\text { Intra-organizational Cooperation } \\
\rightarrow \text { Project Outcome }\end{array}$ & .072 & .092 & .030 & $2.360=$ \\
\hline $\begin{array}{l}\text { Appropriation of Work } \\
\rightarrow \text { Intra-organizational Cooperation }\end{array}$ & .256 & .182 & .057 & $4.477_{* * *}$ \\
\hline $\begin{array}{l}\text { Job Training Satisfaction } \\
\rightarrow \text { Intra-organizational Cooperation }\end{array}$ & .106 & .088 & .049 & 2.175 \\
\hline
\end{tabular}

I've tested the mediating effect of intra-organizational cooperation in relationship between Elderly Employment Project manager's perceived appropriation of work and job training satisfaction and project outcome. The direct effect of appropriation of work to the project outcome can be seen in Fig. 2 as well as the indirect effect through the intra-organizational cooperation on project outcome.

Therefore, there has been bootstrapping to test the mediating effect of the related organization's cooperation. This method estimate the standard errors of direct and indirect effect, which were estimated in the structural model analysis, doing bootstrapping according to the assumption mediating effect distribution does not follow normality. The method also proposes the confidence interval, seeing indirect or direct effect has statistical significance if the interval does not include 0 [18].

I've included total effect, direct effect, and indirect effect and has executed bootstrapping, proposing the detailed content along with the test for mediating effect in Table V. As can be seen, in the appropriation of work's effect on project outcome, the mediating effect of the intra-organizational cooperation does not include 0 in its confidence interval, showing its statistical significance. However, the job training satisfaction does not directly effects the project outcome and showing no significant mediating relationship between the intra-organizational cooperation.

TABLE V: MEDIATING EFFECT

\begin{tabular}{|c|c|c|c|}
\hline Path & $\begin{array}{l}\text { Total } \\
\text { Effect }\end{array}$ & $\begin{array}{l}\text { Direct } \\
\text { Effect }\end{array}$ & $\begin{array}{l}\text { Indirect } \\
\text { effect }\end{array}$ \\
\hline Appropriation of Work & & & \\
\hline $\begin{array}{l}\rightarrow \text { Intra-organizational Cooperation } \\
\rightarrow \text { Project Outcome }\end{array}$ & .168 & .149 & .018 \\
\hline
\end{tabular}

\section{CONCLUSION}

The purpose of the study was to understand the effect of appropriation of work, job training satisfaction, and intra-organizational cooperation has on the project outcome perceived by the Elderly Employment Project's working level officials. Also, it tested the mediating effect of intra-organizational cooperation on the relationship between appropriation of work and job training satisfaction and project outcome.

Based on the analysis results, the intervention plan to improve Elderly Employment Project outcome is as follows.

First, the expansion of financial support is necessary for better outcome of Elderly Employment Project. During last year, there has been quantitative expansion of the project, showing 70,000 increase of project outcome, resulting in the expansion of the related organizations. However, there are limits to the execution of finance related to the working level officials such as expense support or incentives. From the increase in wages of the project participants and expansion of the working level officials and participating organization's finance will the project outcome and effectivity will be higher with solid Elderly Employment Project.

Second, the work analysis and work planning for the working level official's work should be preceded. As this study's result propose, the appropriation of work has statistically significant effect on both project outcome and the related organization's cooperation, as well as the related organization's cooperation's positive effect on the project outcome. Such result proposes that the working level official's perception among division of works, responsible work amount, and responsible work content's appropriateness has effect on the organization's internal/external outcome. To achieve this, the product of work related to the working level officials, the job analysis to analyze the work required for the product, and work design to allocate the work required for the product should be preceded to secure proper appropriation of work for each participating organizations.

Third, there is need to reinforce networking among the project related organizations to improve the Elderly Employment Project outcome.

\section{REFERENCES}

[1] Statistics Korea, "Population prospects of korea," 2005

[2] Ministry of Health and Welfare, "Integrate guidance of 2014 Elderly Employment Project," 2014

[3] Korea Labor Force Development Institute for the Aged. [Online] Available: https://kordi.go.kr/mainSub.do?mCode $=$ B0571

[4] M. G. Kim, "Study on the evaluation of effectiveness of elderly employment project," Korea Labor Force Development Institute for the Aged, pp. 1-90, 2006.

[5] J. Y. Lim and S. W. Lee, "The effect of job creation projects for the elderly on the medical cost of elderly," Health Economy and Policy Research, vol. 14, no. 1, pp. 75-102.

[6] J. W. Go and D. Y. Lee, "The degree of on the life satisfaction and the policy effects of the JOP creation project in the elderly," The Korean Gerontological Society, vol. 31, no. 4, pp.1209-1228, 2011.

[7] P. G. F. Fishman, D. A. Salem, N. A. Allen, and K. Fahrbach, "Facilitating inter-organizational collaboration: the contribution of inter-organizational alliance," American Journal of Community Psychology, vol. 29, no. 6, pp. 875-905, 2001.

[8] S. C. Hwang, M. S. Jung, C. H. Kang, and J. S. Choi, Social Welfare Administration, 1st ed. Seoul, Korea: Hakhyunsa, 2003.

[9] Y. R. Park and G. S. Park, "A Study on the factors influencing the job performance of the senior job placement project coordinators," The Korean Gerontological Society, vol. 30, no. 4, pp. 1059-1075, 2010.

[10] J. E. Gu, "The possibility of the using and limitations of logic model and BSC model for measuring performance in non-profit organizations," Social Science Research Institute, vol. 31, no. 1, pp. 381-407, 2012.

[11] R. L. Daft, Organizational Theory and Design, 9th edition, Vanderbilt University, 2007. 
[12] J. P. Jeun, Y. K. Cho, and Y. J. Park, "The effects of Job characteristics on job satisfaction in nonprofit organizations- focusing on the social welfare organizations," Korea Association of Computer and Accounting, vol. 9, no. 2, pp.105-120, 2011.

[13] Y. G. Shin, Organizational Behavior, Seoul, Korea: Dasan.

[14] L. L. Martin and P. M. Kettner, Measuring the Performance of Human Service Programs, Newbury Park, CA: Sage. 1997.

[15] Y. C. Seo, "The study on the work environment affecting social workers job satisfaction," M.S. thesis, Kukmin Univ., Seoul, Korea, 1993.

[16] Y. J. Moon, "The study on the factors affecting social workers organizational commitment," Korean Social Welfare Administration, vol. 9, no. 1, pp. 53-81, 2007.

[17] S. G. West, J. F. Finch, and P. J. Curran, "Structural equation models with nonnormal variables: problems and remedies," 1995.

[18] P. E. Shrout and N. Bolger, "Mediation in experimental and nonexperimental studies: new procedures and recommendations," Psychological Methods, vol. 7, no. 4, pp. 422, 2002.

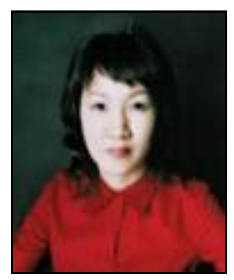

Cin Jae Chang was born in Seoul, Korea on July 10 1967. She received her doctoral degree in social welfare major at Yonsei Graduate School, Seoul, South Korea in 2003. (Thesis: The Factors on the Social Workers' Empowerment in Public Sector)

She worked at Local Government (Nowon-gu, Seoul) as a social worker from July, 1991 to August, 1999. She worked as a researcher for "research for performance analysis and improvement plan of crisis household case management project" in 2009. And she also worked three times as a researcher for projects for the specific local government in 2009, 2010, and 2011.

Now she has been teaching students in Seoul Jangsin University in Gyunggy-do, Korea as an associate professor from 2003. She published a book "Social Welfare Administration, Seoul, Korea: Nanumejip, 2005). Now she is writing her second book "Social Welfare Program Planning and Evaluation". She focused on social welfare administration and public assistance.

Prof. Chang has been directing Academy of Korean Social Welfare Administration from 2005. And she is a member of Child Care and Education Committee of Gwangju Local Government. 